\title{
Individual fish tank arrays in studies of Lepeophtheirus salmonis and lice loss variability
}

\author{
Lars Are Hamre ${ }^{1, *}$, Frank Nilsen ${ }^{1,2}$ \\ ${ }^{1}$ Department of Biology, University of Bergen, PO Box 7800, Bergen 5020, Norway \\ ${ }^{2}$ Institute of Marine Research, PO Box 1870, Nordnes 5817, Norway
}

\begin{abstract}
In studies of the salmon louse Lepeophtheirus salmonis (Krøyer, 1837), experimental design is complicated by a highly variable and unpredictable lice loss among common experimental tanks and a substantial rate of host transfer within tanks. When fish hosting L. salmonis are maintained in individual tanks, unspecific effects such as host transfer, louse predation by cohabitant hosts and agonistic host interactions are excluded. This study suggests that it is possible to maintain Atlantic salmon Salmo salar infected with L. salmonis in an array of small, single fish tanks and, by doing so, provide an experimental system in which the loss of motile pre-adult and adult stages of $L$. salmonis is predictable. Here, lice can be collected shortly after detachment for detailed studies or to provide mortality curves of lice from individual fish. This represents an experimental approach improving precision in studies of $L$. salmonis, such as drug and vaccine efficacy assays, RNA interference (RNAi) studies and host-parasite interactions. The natural loss of pre-adult/adult L. salmonis from the system was higher for males than females. The loss of females appeared to be a process somewhat selective against large individuals. Inherent qualities of the host appeared to be of little significance in explaining the variability in loss of preadult/adult lice.
\end{abstract}

KEY WORDS: Salmon louse $\cdot$ Vaccine $\cdot$ Dose efficacy assay $\cdot$ Drug $\cdot$ Mortality $\cdot$ Loss Resale or republication not permitted without written consent of the publisher

\section{INTRODUCTION}

The salmon louse Lepeophtheirus salmonis is an ectoparasitic copepod causing large economical losses in the fish farming industry (Rae 2002, Johnson et al. 2004, Westcott et al. 2004) and represents a serious threat to wild salmonids (Heuch \& Mo 2001, Butler 2002, Todd et al. 2004). Farmed salmon constitute the vast majority of hosts in several areas, and a substantial part of the total L. salmonis eggs produced originates from lice hosted by farmed fish (Heuch \& Mo 2001, Butler 2002). To avoid a high infection pressure of $L$. salmonis in the sea it is therefore crucial to maintain a low infection level in the fish farms; however, the ability to do this has been compromised by an emerging resistance towards an already limited number of available drugs (Jones et al. 1992, Sevatdal \& Horsberg 2003, Sevatdal et al. 2005, Lees et al. 2008).
The life-cycle of Lepeophtheirus salmonis is characterised by 10 stages, each separated by a moult (Johnson \& Albright 1991b). This involves 2 planktonic non-feeding nauplii stages, a planktonic and infective copepodid stage, 4 chalimi stages in which the parasite is permanently attached to the host by a frontal filament, 2 motile pre-adult stages (I and II) and the final motile adult stage, where the motile stages are attached by filament only upon moulting (Johnson \& Albright 1991a). High and very variable unspecific loss of lice has been observed between experimental tanks during development (Bjorn \& Finstad 1998, Tucker et al. 2002a, Hamre et al. 2009) and a significant rate of host transfer has been observed within tanks (Ritchie 1997, Hull et al. 1998). This complicates experimental design in several fields of $L$. salmonis research, in particular with respect to long-lasting efficacy assays such as evalu- 
ation of test vaccines against L. salmonis (Grayson et al. 1995, Roper et al. 1995, Pike \& Wadsworth 1999, Raynard et al. 2002). Hosting L. salmonis in tanks with many small fish results in a considerably more unpredictable loss of lice, and female lice are lost at a higher rate than males (Hamre et al. 2009). Specific laboratory strains of $L$. salmonis have been established, and it has been shown that large host fish stocked at low density constitute a relatively stable environment for maintaining cohorts of L. salmonis over time, providing conditions where females generally are lost at a slightly lower rate than males (Hamre et al. 2009). Experience with cod lice Caligus curtus cultures show that the loss was reduced and became less variable when the hosts were maintained individually (Hamre \& Nilsen 2007). We, therefore, hypothesize that solitaire L. salmonis hosts maintained in small single fish tanks reduce unspecific lice loss and increase experimental precision. In this study, we evaluate the results of 4 separate experiments and (1) assess whether it is feasible to maintain small salmon infected with $L$. salmonis in a set of small single fish test tanks by observing growth and behaviour of fish, (2) examine the between-host variability in lice loss and its possible causes among individual fish maintained in single fish tanks, and (3) discuss the experimental potential of such a system with respect to efficacy assays and other fields of fish lice research.

\section{MATERIALS AND METHODS}

We conducted 4 successive and separate experiments (Trials 1 to 4) (Table 1) at the Institute of Marine Research in Bergen, Norway. The general experimental scheme involved culturing a set of reservoir lice to the pre-adult/adult stage, whereby 8 female and 8 male pre-adult/adult lice were removed from their original host and placed on new host fish that were subsequently put in 20 small single fish

Table 1. Date of start, duration of experiment in $d$ and degree days (DD), ambient water temperature (Temp.) and age of Lepeophtheirus salmonis. Lice age: age of lice at sampling given as days post the initial infection with copepodids

\begin{tabular}{|c|c|c|c|c|c|}
\hline \multirow[t]{2}{*}{ Trial } & \multirow{2}{*}{$\begin{array}{l}\text { Start date } \\
\text { (d/mo/yr) }\end{array}$} & \multicolumn{2}{|c|}{ Duration } & \multirow{2}{*}{$\begin{array}{l}\text { Temp. } \\
\left({ }^{\circ} \mathrm{C}\right)\end{array}$} & \multirow{2}{*}{$\begin{array}{l}\text { Lice age } \\
\text { (d) }\end{array}$} \\
\hline & & $\mathrm{d}$ & $\mathrm{DD}$ & & \\
\hline 1 & $30 / 06 / 2008$ & 24 & 235 & 9.8 & 48 \\
\hline 2 & $24 / 07 / 2008$ & 40 & 404 & 10.1 & 70 \\
\hline 3 & $26 / 11 / 2008$ & 40 & 380 & 9.5 & 70 \\
\hline 4 & $13 / 01 / 2009$ & 48 & 370 & 7.7 & 84 \\
\hline
\end{tabular}

tanks (Trials 1-4) and a 2001 tank containing 20 fish (Trials 1 and 2). After a period of between 24 and 48 $\mathrm{d}$ the fish were sampled (see Table 1). Length and weight of the host fish were recorded at the beginning and end of each trial to assess growth (Trials 2 to 4). Each of the individual tank outlets was fitted with a net (1000 $\mu \mathrm{m}$ mesh), and daily lice loss was measured by collecting detached lice during Trial 4. At sampling, lice and egg strings were counted and photographed. Incubation of eggs and infection of reservoir fish with copepodids were carried out according to Hamre et al. (2009). Lice belonging to the LsGulen laboratory strain (F8-F10) were used in all 4 trials (see Hamre et al. 2009).

The fish maintained individually were kept in an array of 20 small single fish tanks that were made of transparent, 551 commercial plastic (PE) (Nordiska Plast AB, www.nordiska-plast.se) measuring $50 \times 34$ $\times 35 \mathrm{~cm}$ (internal measurements) (Fig. 1). Water was fed to the small tanks by a perforated $32 \mathrm{~mm}$ tube going through all tanks (Fig. 1) so that each tank received an equal water supply $7 \mathrm{~cm}$ above the bottom. The outlet was situated on the opposite side of the inlet, $17 \mathrm{~cm}$ above the bottom, in an attempt to establish a 1-way current through the tank for the fish to stay in. Water volume was 281 and the flow was $41 \mathrm{~min}^{-1}$. The tanks were located outdoors. The 2001 fish tank was placed indoors and had a flow of $7 \mathrm{l} \mathrm{m}^{-1}$ (description in Hamre et al. 2009). Sea water was collected at a depth of $90 \mathrm{~m}$.

In Trial 1 pre-adult I females and pre-adult II males were attached to 40 experimental fish: 20 fish were placed individually in the small test tanks and 20 fish were placed in the $200 \mathrm{l}$ tank in order to compare lice loss and fish growth in the 2 systems. The duration of the experiment was $24 \mathrm{~d}$. Trial 2 was initiated immediately after sampling of Trial 1 using the same fish. A new batch of pre-adult II females and adult males were attached to the fish immediately after the previous lice had been removed and the fish were returned to their respective tanks. Details on temperature, time and duration of all trials are given in Table 1.

Trial 3 and 4 were duplicate trials originally designed to test the effect of the vaccine antigen candidate LsYAP (maternal yolk-associated protein) (Dalvin et al. 2009) against a BSA-injected control group. Except for the vaccination of fish, the experimental setup was similar to Trial 2, using seperate batches of fish but in the small test tanks only; with slightly varying ambient water temperatures and a prolonged experimental period (48 d) in Trial 4. The trials were carried out solely in the small test tanks on 


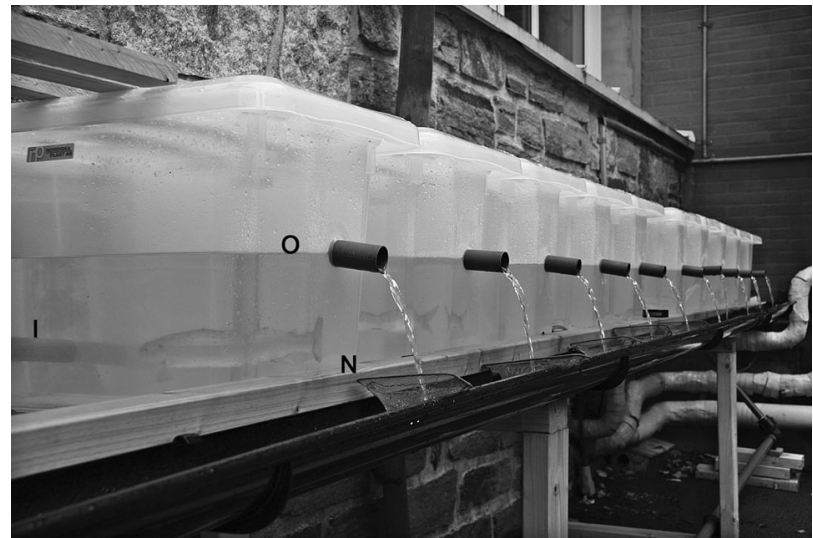

Fig. 1. Single fish test tanks containing 1 fish $\operatorname{tank}^{-1}$. N: net collecting detached lice from outlet water, I: water inlet, O: water outlet

separate batches of fish, and Trial 4 was initiated shortly after the end of Trial 3 (Table 1). The vaccine did not have any effect on either lice loss or fitness parameters compared to the control in either of the trials (authors' unpubl. data); thus, the data obtained were pooled and presented here.

The reservoir lice for Trial 1 were cultured in an indoor $500 \mathrm{l}$ tank $(1 \times 1 \times 0.5 \mathrm{~m}, 12 \mathrm{~h}$ light:12 h dark); for Trials $2-4$, the reservoir lice were cultured in outdoor 15001 circular tanks. Prior to handling, all fish were anaesthetized by a mixture of $60 \mathrm{mg} \mathrm{l}^{-1}$ benzocaine and $5 \mathrm{mg} \mathrm{l}^{-1}$ methomidate. The fish were hand fed ad libitum once a day using a commercial diet and maintained according to Norwegian animal welfare regulations.

Mean lice abundance during Trial 4 was estimated for each day of the experiment by subtracting the cumulative number of lice collected in the nets from the number of lice initially placed on the fish. The daily instantaneous loss rate was calculated as:

$$
r=-\ln \left(N_{T 1} / N_{T 2}\right) / \Delta T
$$

where $r$ = daily instantaneous loss rate, $N=$ number of lice, and $\Delta T=$ number of days between $T_{1}$ and $T_{2}$, i.e. start and end of the experiment, respectively. Images of whole lice with egg strings were obtained using a Canon EOS 30D camera and a $60 \mathrm{~mm}$ macro lens (lice placed on wet, white absorbent paper, lit from below). Morphometric measurements of lice and eggs were carried out on lice hosted by fish in single fish tanks using the ImageJ image analysis software (http://rsb.info.nih.gov/ij). All statistical calculations on morphometric and infection data were carried out using Statistica 8.0 (www.statsoft.com). Power analysis was performed using GraphPad
StatMate 2.00 (http://www.graphpad.com/StatMate/ statmate.htm).

Spearman's rank correlation was used to test whether the loss from individual fish in Trial 1 was correlated to the loss from the same individual fish in Trial 2, and whether the loss of males was correlated with the loss of females (all trials). Simple analyses of variance (ANOVA) and covariance (ANCOVA) were used to test for differences in lice loss between trials. Data from Trials 2-4 (single fish tanks) were pooled and simple regression was used to describe the relationship between lice loss and host size. Simple regression was also used to describe the relationship between cephalothorax length and louse size for both male and female lice within each trial. All statistical tests were performed using Statistica 8.0.

Specific growth rate (SGR) was calculated as:

$$
\mathrm{SGR}=\left(\ln W_{\text {end }}-\ln W_{\text {start }}\right) / \Delta T
$$

where $W=$ fish weight, $\Delta T=$ number of days between times $T_{1}$ and $T_{2}$. Host surface area was calculated according to Glover et al. (2004a). The parasitological terms used are in accordance with Bush et al. (1997).

\section{RESULTS}

\section{Fish welfare}

While the fish in the communal tank started eating the day after the start of experiment, the first fish in the single fish tanks lined up in the current of flow at Day 2 and started eating on Day 3. After $\sim 1 \mathrm{wk}$, most of the fish had started eating. The fish were eager to take food and were otherwise surprisingly calm upon feeding and inspection. It is also our impression that over time the fish became better at collecting pellets from the tank bottom. Particles from excess food were flushed from the tanks and water quality was good (visual inspection). Some forward water flow towards the water inlet was observed along the sides of the tanks. The condition factor of the fish hosted in the single fish tanks were significantly lower than those hosted in the communal tank in Trial 1 (t-test, $t=6.2, \mathrm{p}<0.0001$ ) (Table 2); however, after the fish had adapted to their new environment, the SGR was similar in single fish tanks and the common tank (Trial 2, Table 2). The infection level applied caused little observable damage to the host, and only a few cases of moderate skin erosion were observed with the exception of 3 fish that were euthanized due to skin wounds in Trial 4. These were not typical 
Table 2. Salmo salar. Mean length $(L)$ and weight $(W)$ of host fish upon sampling in Trials 1-4. Minima-maxima given in brackets. Cfac: Fulton's condition factor $=W /\left(L^{3}\right)$. SGR: specific growth rate. nd: not determined

\begin{tabular}{|lcccccc|}
\hline \multirow{2}{*}{ Trial } & Tank type & $\mathrm{n}$ & $L(\mathrm{~cm})$ & $W(\mathrm{~g})$ & Cfac & SGR (\%) \\
\hline \multirow{2}{*}{1} & Single & 20 & $23.3(20-26)$ & $131(92-195)$ & 1.03 & $\mathrm{nd}$ \\
& Communal & 20 & $23.4(20-28)$ & $165(119-246)$ & 1.28 & nd \\
2 & Single & 20 & $24.9(21-28)$ & $154(100-234)$ & 0.99 & 0.41 \\
& Communal & 20 & $26.4(24-30)$ & $191(141-291)$ & 1.03 & 0.37 \\
3 & Single & 20 & $26.4(25-29)$ & $195(127-252)$ & 1.05 & 0.34 \\
4 & Single & 17 & $28.6(26-31)$ & $244(196-311)$ & 1.04 & 0.36 \\
\hline
\end{tabular}

Table 3. Lepeophtheirus salmonis. Loss of lice from Atlantic salmon Salmo salar maintained in communal and single fish tanks. Fish were given an infection of 8 pre-adult I females and 8 pre-adult II males (Trial 1) or 8 preadult II females and 8 adult males (Trials 2-4). Losses were evaluated after 24, 40, 40 and $48 \mathrm{~d}$ for Trials 1-4, respectively. Mean abundance: mean number of $L$. salmonis fish ${ }^{-1}$ upon sampling; lice lost: lice lost during experiment (\%). F and M: mean abundances of females and males; $r_{\mathrm{F}}$ and $r_{\mathrm{M}}$ : \% female and male instantaneous daily loss rate. SD given in brackets

\begin{tabular}{|cccccccccc|}
\hline Trial & Tank & $\begin{array}{c}\text { Mean } \\
\text { abundance }\end{array}$ & F & M & $\begin{array}{c}\text { M:F } \\
\text { ratio }\end{array}$ & $\begin{array}{c}\text { Lice } \\
\text { lost }(\%)\end{array}$ & $\begin{array}{c}r_{\mathrm{F}} \\
(\%)\end{array}$ & $\begin{array}{r}r_{\mathrm{M}} \\
(\%)\end{array}$ \\
\hline 1 & Single & $9(2.6)$ & $4.2(1.5)$ & $4.8(1.6)$ & 1.14 & 44 & 2.7 & 2.1 \\
& Communal & $9.7(3.4)$ & $4.4(1.6)$ & $5.4(2.4)$ & 1.23 & 39 & 2.5 & 1.7 \\
2 & Single & $7.9(1.6)$ & $4.3(1.1)$ & $3.6(1.1)$ & 0.83 & 51 & 1.6 & 2.0 \\
& Communal & $10.2(2.2)$ & $4.3(1.4)$ & $6(2.3)$ & 1.4 & 36 & 1.6 & 0.7 \\
3 & Single & $8.5(2.7)$ & $4.9(1.7)$ & $3.6(1.5)$ & 0.72 & 47 & 1.2 & 2.0 \\
4 & Single & $9.5(2.3)$ & $5.7(1.4)$ & $3.8(1.7)$ & 0.66 & 41 & 0.7 & 1.6 \\
\hline
\end{tabular}

While the loss of males remained constant, the loss of female lice varied significantly among Trials 2-4 (ANOVA, $F_{2,54}=$ 6.01, $\mathrm{p}<0.005$; Fig. 3A). However, the host size used increased in Trials 2-4 (Table 2). When adding host size as a covariate, the loss of females did not vary significantly among trials (ANCOVA, $\left.F_{2,53}=0.65, \mathrm{p}<0.53\right)$. Pooled data from Trials 2-4 show that the number of females lost decreased significantly with host weight (linear regression, $F_{1,55}=$ 13.03, $\mathrm{p}<0.0007, \mathrm{R}^{2}=0.19, y=2.02-$ $0.0035 x$ ) while the loss of males did not vary with host size (linear regression, $F_{1,55}=3.63, \mathrm{p}<0.06, \mathrm{R}^{2}=0.06, y=1.94-$ $0.0008 x)$. Consequently, the density of females (lice $\mathrm{cm}^{-2}$ ) remained constant while the density of males displayed a decreasing trend among Trials 2-4 (Fig. 3B).

Louse size and egg string length varied among trials (Fig. 4). Also, the mean cephalothorax length of the remaining females decreased significantly with the number of females lost from their respective hosts, i.e. Trial 2: $F_{1,18}=5.65, \mathrm{p}<$ $0.029, \mathrm{R}^{2}=0.24, y=4.55-0.032 x_{;}$Trial 3: $F_{1,18}=4.87, \mathrm{p}<0.041, \mathrm{R}^{2}=0.21, y=4.47-$ $0.023 x ;$ and Trial 4: $F_{1,15}=4.01, \mathrm{p}<0.064$, $\mathrm{R}^{2}=0.21, y=4.59-0.031 x$ (Fig. 5). Mean egg string length of the remaining wounds caused by Lepeophtheirus salmonis, and microscopy (smear from wounds) revealed a high density of Flexibacter-like bacteria. Such infections occur from time to time on salmon in the laboratory during winter and are probably related to a deep water intake (90 m).

\section{Lice loss and host-parasite relationship}

A grand total of 38 and $46 \%$ of the Lepeophtheirus salmonis added to the fish were lost from communal and single fish tanks, respectively, during the trials. While the loss of female L. salmonis was similar, the loss of males was higher from single fish tanks than communal tanks, although significant only in Trial 2 $(t=4.24, \mathrm{p}<0.001)$ (Table 3, Fig. 2). The male:female sex ratio was $>1$ in communal tanks at the end of both Trials 1 and 2 (Table 3), but in single fish tanks, with the exception of Trial 1, which followed a different experimental protocol than Trials 2-4, the male: female ratio was $<1$ (Table 3 ). females displayed a decreasing, but not significant trend with female loss (linear regression). The size of

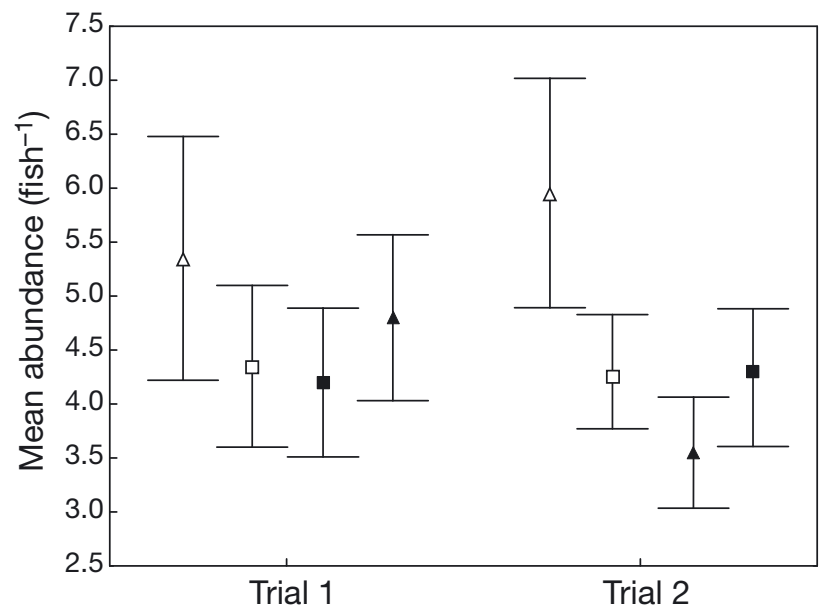

Fig. 2. Lepeophtheirus salmonis. Mean abundance of female (squares) and male (triangles) lice per fish in single and common tanks in Trial 1 and 2. Filled symbols: single fish tanks; unfilled: communal tanks. Whiskers $=95 \% \mathrm{CI}$ 

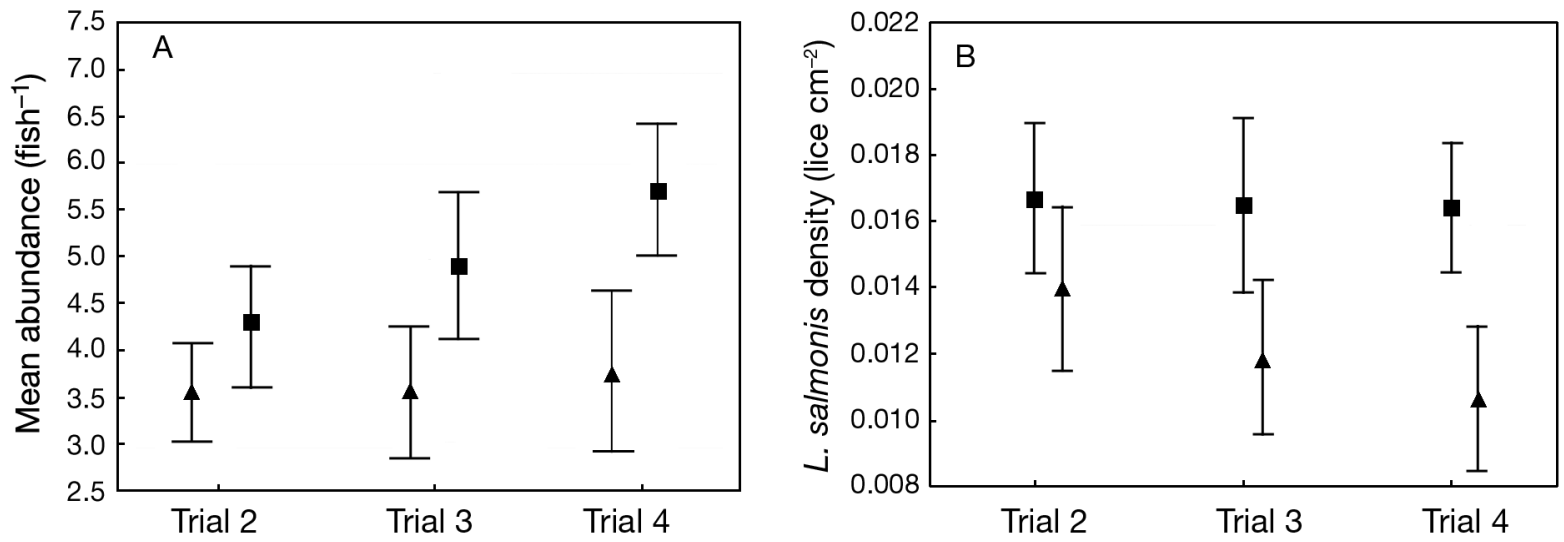

Fig. 3. Lepeophtheirus salmonis. Mean (A) abundance (fish ${ }^{-1}$ ) and (B) density (lice $\mathrm{cm}^{-2}$ ) of lice remaining on hosts in single fish tanks in Trials 2-4. Squares: females; triangles: males. Note that the trials were carried out in succession and the host fish used were increasingly larger (see Table 2 for details). Whiskers $=95 \% \mathrm{CI}$
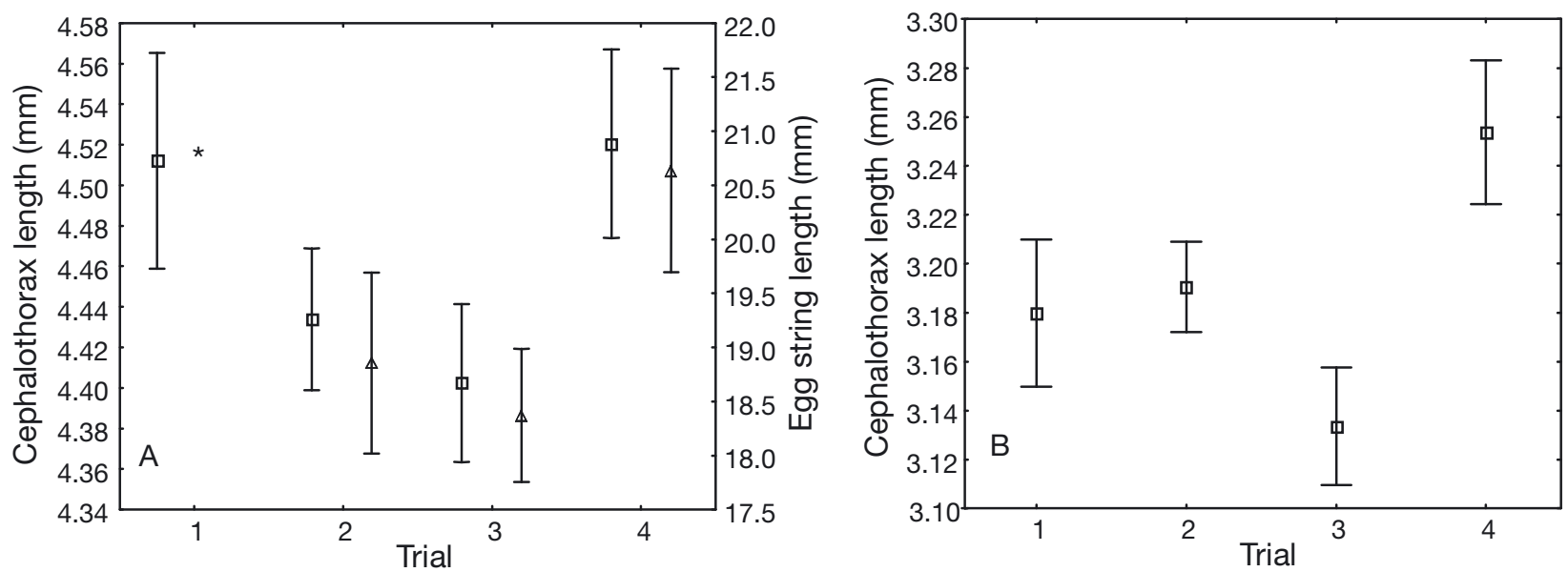

Fig. 4. Lepeophtheirus salmonis. Length of adult (A) female cephalothorax ( $\square$, left axis) and egg strings ( $\Delta$, right axis), and (B) male cephalothorax, at sampling in Trials 1-4. Whiskers $=95 \%$ CI. Data based on 307 males and 367 females. *: sampled before start of egg production

the remaining males was not related to the number of males lost (linear regression). Furthermore, the loss of female lice was not correlated to the loss of male lice from individual hosts in single fish tanks in any of the trials (Spearman's rank order correlation). Among the single fish tanks in Trial 1, host size and size of the remaining lice did not vary with lice loss (linear regression). Also, there was no correlation between lice loss in Trial 1 and the loss experienced by the same individual hosts in Trial 2 (Spearman's rank correlation).

Although only $\sim 70 \%$ of the males and females lost were collected in the nets during Trial 4, the estimates on daily lice loss based on these data show that both sexes were lost at a similar rate between Days 1 and 12 , the mean instantaneous daily loss rate being
0.8 and $0.7 \%$ for males and females, respectively, over this period. For the remaining $36 \mathrm{~d}$, the estimated loss rate was higher for males $(0.8 \%)$ than for females (0.2\%) (Fig. 6).

\section{Power analysis}

The basic loss of Lepeophtheirus salmonis observed during Trials 1-4 and the resulting distribution of lice provide a basis for evaluating the use of single fish tanks in $L$. salmonis efficacy assays. Table 4 shows the difference between means that can be detected at a given sample size with $80 \%$ power and $\alpha=0.05$, using a 1 -tailed $t$-test and the standard deviations observed in Trials 1-4 (SD listed 

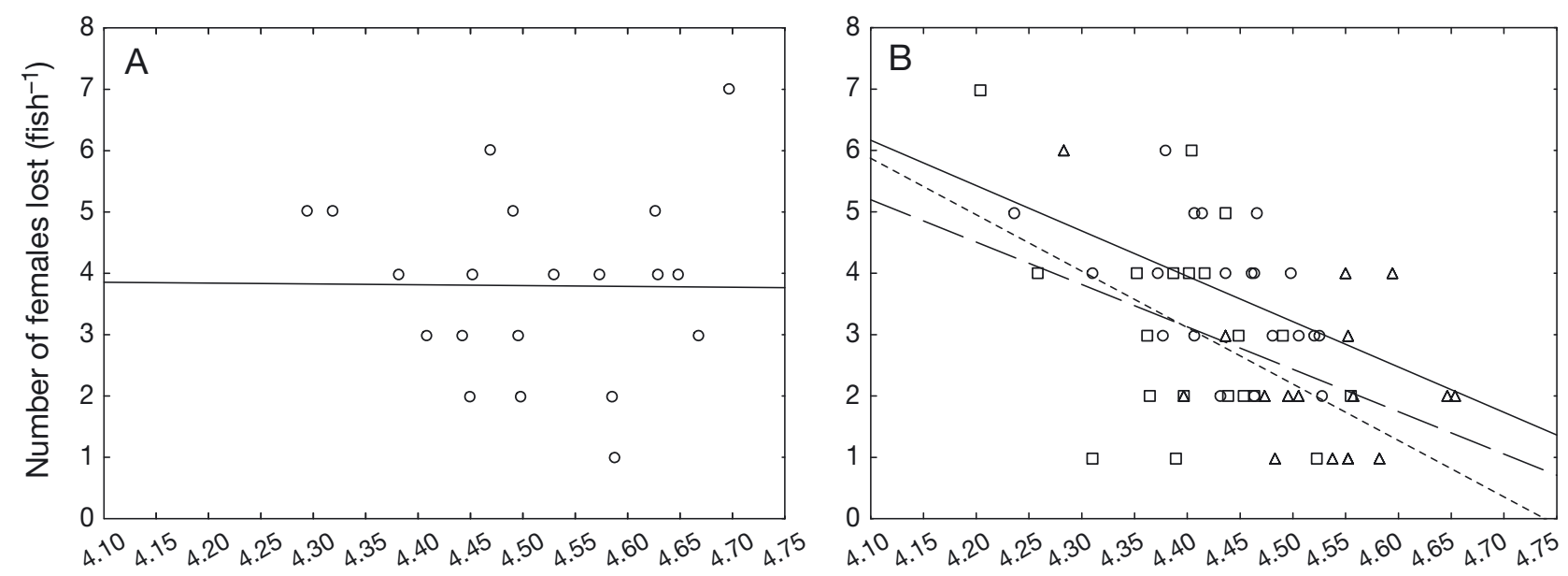

Cephalothorax length ( $\mathrm{mm}$ )

Fig. 5. Lepeophtheirus salmonis. Number of females lost in single fish tanks vs. cephalothorax length of remaining females. (A) Trial 1, and (B) Trial 2 (O, solid line), Trial 3 ( $\square$, short dashed line), Trial 4 ( $\triangle$, long dashed line)

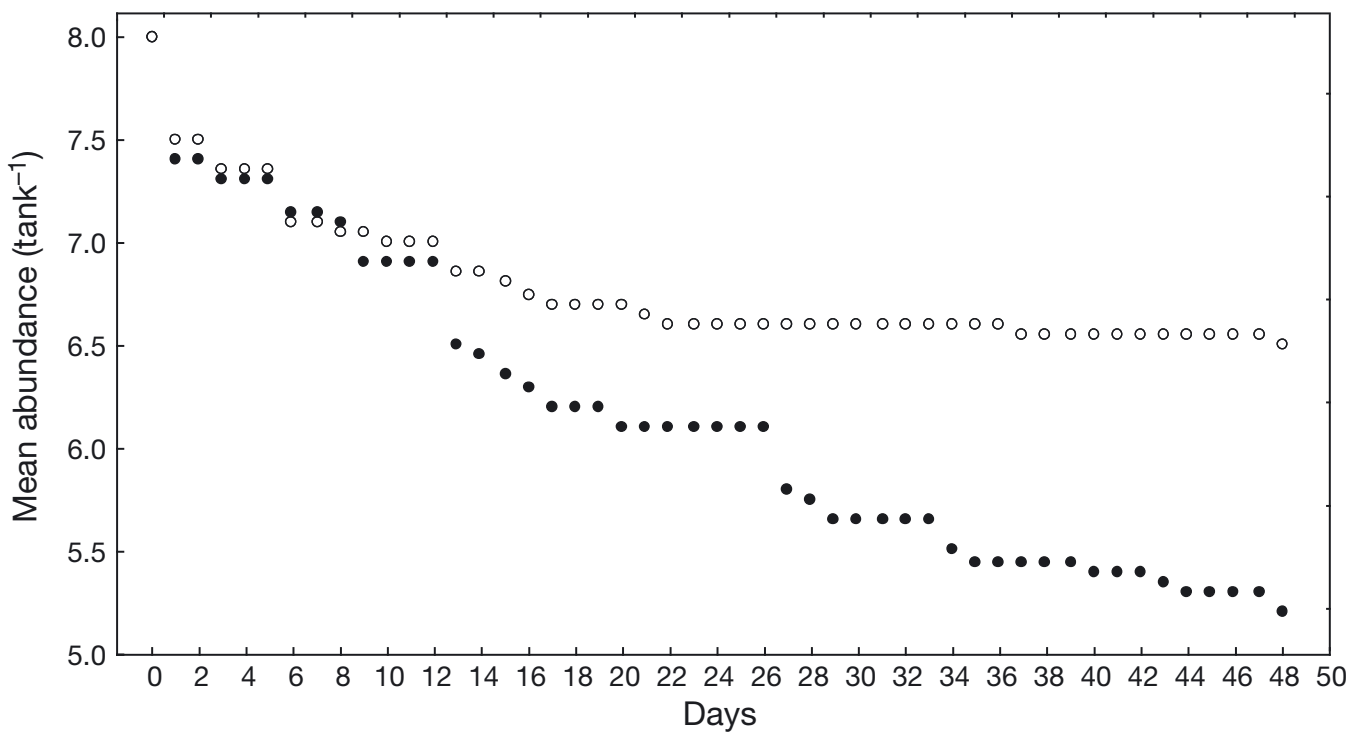

Fig. 6. Lepeophtheirus salmonis. Estimated mean abundance of male ( $\bullet$ ) and female (O) lice on fish during the course of Trial 4, estimated by subtracting the cumulative number of lice strained from the outlet water from the number of lice added (8 females, 8 males per fish) at start of experiment. Note 67 and $69 \%$ of females and males lost, respectively, were collected in the nets; thus, the graph represents an overestimate of lice abundance (see 'Discussion')

in Table 3). Given the present experimental design, this suggests that an efficacy assay designed to detect $\leq 50 \%$ effect on lice loss requires between 3 and 6 fish group ${ }^{-1}$.

\section{DISCUSSION}

High quality experimental facilities and robust procedures for experimental infections with economical important parasites like salmon louse are crucial for future development of new treatment tools and to expand our knowledge about sea lice in general. Few parasite model systems exist and, due to the parasitic lifestyle, manipulation of these organisms is often very difficult. Recently, we have establish an efficient system for breeding and maintaining salmon louse strains (Hamre et al. 2009), and here we present a novel system for conducting high quality experiments with salmon louse. Single fish tanks provide an environment for hosting Lepeophtheirus salmonis where each fish represents an independent experimental 
Table 4. Percent effect of treatment on lice loss that can be detected with $80 \%$ power and $\alpha=0.05$ at a given sample size of host fish by means of a 1-tailed $t$-test. Values were calculated based on mean abundance of lice and SD resulting from natural loss of Lepeophtheirus salmonis from fish in single fish tanks in each of Trials 1-4

\begin{tabular}{|lcccc|}
\hline $\begin{array}{l}\text { Sample } \\
\text { size }\end{array}$ & $\begin{array}{c}\text { Trial } 1 \\
(\%)\end{array}$ & $\begin{array}{c}\text { Trial 2 } \\
(\%)\end{array}$ & $\begin{array}{c}\text { Trial 3 } \\
(\%)\end{array}$ & $\begin{array}{c}\text { Trial 4 } \\
(\%)\end{array}$ \\
\hline 3 & 69 & 48 & 76 & 58 \\
4 & 57 & 40 & 62 & 48 \\
5 & 49 & 35 & 54 & 41 \\
6 & 44 & 31 & 49 & 37 \\
7 & 41 & 28 & 45 & 34 \\
8 & 38 & 26 & 42 & 32 \\
9 & 35 & 25 & 39 & 30 \\
10 & 33 & 23 & 37 & 28 \\
\hline
\end{tabular}

unit as opposed to communal tanks where the infection level of a host is dependent on the other hosts present due to host change and louse predation by cohabitants (Morton \& Routledge 2005). In the present study, we have demonstrated that small transparent tanks provide an environment where small salmon infected with salmon lice thrive, in which the natural variability of lice loss from tanks is predictable and which allows efficacy assays to be carried out using single fish tank arrays within practical size limits. The system provides the means to collect detached lice shortly after detachment and to obtain precise mortality curves from individual hosts. In this way, more precise effects on both lice loss and the detached lice themselves can be measured in RNA interference (RNAi) and vaccine studies on motile L. salmonis. This also allows efficient and precise dose-efficacy assays to be performed in an array of tanks where individual bath treatments can be given to each host fish, or alternatively, where individual host-feeding can be monitored. Furthermore, host transfer (Ritchie 1997, Hull et al. 1998) and agonistic host behaviour (Dawson et al. 1999) does not obscure vital information on host-parasite relationship; thus, the system will increase precision in a wide range of studies.

\section{Single fish tank performance}

The ideal single fish tank array consists of small tank units in which solitaire fish thrive. Lice detaching from the host fish should be collected immediately after detachment and not be given the chance to re-attach or to be eaten by its host fish. To achieve this, the test tanks used were transparent to reduce the impression of space restriction and to avoid fright reactions caused by sudden visual cues from above (which occur when approaching common tanks with non-transparent side walls; authors' pers. obs.). The water inlet and outlet were placed at opposite ends of the tank providing a directional flow of current through the tank. Food was administered at the water inlet attempting to motivate the fish to remain in the flow of current hunting for food. The results showed that the fish lined up relatively quickly in the current flow, had good appetite and were calm upon feeding and inspection. It is, however, apparent that the fish needed a longer time to adapt to the single fish tanks as compared to the communal tank, which after all represents an environment that the fish are already used to. This is also reflected in the lower condition factor observed among the fish hosted in the single fish tanks in Trial 1. However, after the fish had adapted to the new environment (Trial 2), the SGR was similar in the 2 tank types (Table 2) and not different from growth rates observed in other studies using communal tanks (Dawson et al. 1999).

The nets straining the outlet water collected $\sim 70 \%$ of the lice lost, suggesting that the test tanks used were somewhat sub-optimal with respect to precise registration and collection of detached lice. However, the test tanks were placed outdoors and wind often deflected the outlet water from the nets, or at times even removed some of the nets. Also, a forward moving current was observed along the sides of the tanks, thus allowing detached lice to be carried forward and eaten. On several occasions, lice were observed on the tank walls, and on a few occasions, decayed lice were found in the nets. Nevertheless, if imperfect filtering explained the majority of the unaccounted lice rather than the lice being eaten, the present tank units can be well suited for use in a single fish tank array. This question will, however, be answered when the tanks are mounted indoors with proper filtering.

\section{Lice loss}

The present study showed that the lice loss from individual fish in Trial 2 was independent of that experienced from the same fish in Trial 1. This is in accordance with the observations of Glover et al. (2004b) and Glover \& Skaala (2006), and suggest that inherent lice-rejecting properties of the hosts may not have been a major factor explaining the observed variation in lice loss. The lack of correlation between male and female loss in all trials may also be indicative of this, suggesting that the loss of male and 
female lice are caused by independent mechanisms. Furthermore, if the host's immune response played a significant role in loss of pre-adult/adult lice, this did not affect food uptake or digestion among the remaining female lice since egg production was independent of the magnitude of lice loss from the host.

Several reports show that abundance of Lepeophtheirus salmonis increases with host size (Jaworski \& Holm 1992, Glover et al. 2001, 2004a,b, Tucker et al. 2002b, Costello 2006). In the present study, the host size range was small within trials, and it was difficult to obtain reliable information on the relationship between host size and lice loss. However, both the number of remaining females and host size increased successively in Trials 2-4, and host size alone could account for the variation in female loss among trials. Hence, we find it likely that the loss of female lice was host size dependent. Furthermore, hosts with a high loss of females also carried smaller females at sampling. Size-dependent loss rather than differential growth may explain this trend since the lice were almost fully grown at the start of the experiment. The trend was not observed in Trial 1, which was terminated $\sim 1$ wk after the females moulted into adults and before extrusion of first egg strings. Thus, it may appear that this selective loss mechanism is at play predominantly among adult females. Host anti-louse behaviour, like jumping and scratching, can in theory cause a size-dependent lice loss favouring the retention of smaller adult females.

Despite the fact that host size increased, the loss of males remained constant from the single fish tanks in Trials 2-4, and there was no significant relationship between host size and the loss of male lice in the pooled dataset. Since the male loss appears to be differentially influenced by host size compared to females, the sex ratio of adult Lepeophtheirus salmonis may in part be determined by host size. This concurs with previous studies showing that males are lost at a higher rate than females from large host fish (Hamre et al. 2009) and at a lower rate than females from small fish in communal tanks (Bjorn \& Finstad 1998, Tucker et al. 2002a, Hamre et al. 2009). Host density may also be a factor explaining the sex ratio of L. salmonis in experimental tanks. The loss of male lice from the communal tank in Trial 2 was significantly lower than from the single fish tanks, while the loss of female lice was similar (Table 3, Fig. 2). Hull et al. (1998) demonstrated that the adult male inter-host transfer rate was 3.5 times higher than for adult mated females (see also Jaworski \& Holm 1992). Thus, the observed differential loss rate can be explained if male detachment is followed by reattachment among densely stocked hosts in communal tanks and loss in single fish tanks. The fact that the male:female sex ratio of adult $L$. salmonis is commonly <1 among wild hosts (Jacobsen \& Gaard 1997, Tingley et al. 1997, Todd et al. 2000, Copley et al. 2005) and >1 among farmed hosts (Bron et al. 1993, Todd et al. 2000) may also reflect this.

As demonstrated by Todd et al. (2005), polyandry is common among Lepeophtheirus salmonis. This implies that after the initial mating with virgin females, males engage in further mating attempts on mature fertilized females carrying protective spermatophores from the first mating (Todd et al. 2005). In Trial 4, most of the female population had molted into adults and become fertilized at age $48 \mathrm{~d}$ (Day 12, Fig. 4). Despite this, the daily instantaneous loss rate of males was not different during the first $12 \mathrm{~d}$ compared to the latter $36 \mathrm{~d}$ of the experiment. This suggests that the combined risk involved in male mating activity (mate search, competition for females and mating itself) did not change with the change in female population from pre-adults to mated adult females. The loss rate of females, on the other hand, was reduced post molting and/or fertilization (Fig. 4), and the male loss rate during the latter $36 \mathrm{~d}$ of the experiment was consequently higher than for females.

\section{CONCLUSION}

We have shown that hosting lice on solitaire hosts in an array of single fish tanks is a feasible experimental approach since fish are able to thrive in the tanks and the natural loss of lice from the system is stable. Since the variability in lice loss between communal tanks can be high (see 'Introduction'), this system represents a tool that improves experimental precision in studies of sea lice. An array of small individual tanks may facilitate large-scale screening of drugs, RNAi candidate genes and vaccine components since few hosts are required for detection of abnormal lice loss. The loss of adult females appeared to be a process somewhat selective against large individuals, and we suggest that both host size and host density are factors determining the lice loss and sex ratio of adult Lepeophtheirus salmonis in experimental tanks. We did not find evidence suggesting that individual variation in host immune response was a vital factor explaining the variation in loss of pre-adult/adult lice. However, dedicated studies are required to draw reliable conclusions on this topic. 
Acknowledgements. We thank C. Sunde and L. Ljungfeldt for their technical assistance. This research was supported by the FUGE program and the HAVBRUK in the Norwegian Research Council.

\section{LITERATURE CITED}

Bjorn PA, Finstad B (1998) The development of salmon lice (Lepeophtheirus salmonis) on artificially infected post smolts of sea trout (Salmo trutta). Can J Zool 76:970-977

Bron JE, Sommerville C, Wootten R, Rae GH (1993) Fallowing of marine Atlantic salmon, Salmo salar L, farms as a method for the control of sealice, Lepeophtheirus salmonis (Kroyer, 1837). J Fish Dis 16:487-493

Bush AO, Lafferty KD, Lotz JM, Shostak AW (1997) Parasitology meets ecology on its own terms: Margolis et al. revisited. J Parasitol 83:575-583

Butler JRA (2002) Wild salmonids and sea louse infestations on the west coast of Scotland: sources of infection and implications for the management of marine salmon farms. Pest Manag Sci 58:595-608

> Copley L, Tierney TD, Kane F, Naughton O and others (2005) Sea lice, Lepeophtheirus salmonis and Caligus elongatus, levels on salmon returning to the west coast of Ireland, 2003. J Mar Biol Assoc UK 85:87-92

> Costello MJ (2006) Ecology of sea lice parasitic on farmed and wild fish. Trends Parasitol 22:475-483

Dalvin S, Frost P, Biering E, Hamre LA, Eichner C, Krossoy B, Nilsen F (2009) Functional characterisation of the maternal yolk-associated protein (LsYAP) utilising systemic RNA interference in the salmon louse (Lepeophtheirus salmonis) (Crustacea: Copepoda). Int J Parasitol 39:1407-1415

> Dawson LHJ, Pike AW, Houlihan DF, McVicar AH (1999) Changes in physiological parameters and feeding behavior of Atlantic salmon Salmo salar infected with sea lice Lepeophtheirus salmonis. Dis Aquat Org 35:89-99

Glover KA, Skaala O (2006) Temporal stability of sea louse Lepeophtheirus salmonis Krøyer populations on Atlantic salmon Salmo salar L. of wild, farm and hybrid parentage. J Fish Biol 68:1795-1807

> Glover KA, Nilsen F, Skaala O, Taggart JB, Teale AJ (2001) Differences in susceptibility to sea lice infection between a sea run and a freshwater resident population of brown trout. J Fish Biol 59:1512-1519

Glover KA, Hamre LA, Skaala O, Nilsen F (2004a) A comparison of sea louse (Lepeophtheirus salmonis) infection levels in farmed and wild Atlantic salmon (Salmo salar L.) stocks. Aquaculture 232:41-52

> Glover KA, Nilsen F, Skaala O (2004b) Individual variation in sea lice (Lepeophtheirus salmonis) infection on Atlantic salmon (Salmo salar). Aquaculture 241:701-709

Grayson TH, John RJ, Wadsworth S, Greaves K and others (1995) Immunization of Atlantic salmon against the salmon louse: identification of antigens and effects on louse fecundity. J Fish Biol 47:85-94

Hamre LA, Nilsen F (2007) New data on life cycle of Caligus curtus and establishment of laboratory strains. Parassitologia 49:287

> Hamre LA, Glover KA, Nilsen F (2009) Establishment and characterisation of salmon louse (Lepeophtheirus salmonis (Krøyer 1837)) laboratory strains. Parasitol Int 58: 451-460

- Heuch PA, Mo TA (2001) A model of salmon louse produc- tion in Norway: effects of increasing salmon production and public management measures. Dis Aquat Org 45: $145-152$

> Hull MQ, Pike AW, Mordue AJ, Rae GH (1998) Patterns of pair formation and mating in an ectoparasitic caligid copepod Lepeophtheirus salmonis (Krøyer 1837): implications for its sensory and mating biology. Philos Trans R Soc Lon B 353:753-764

Jacobsen JA, Gaard E (1997) Open-ocean infestation by salmon lice (Lepeophtheirus salmonis): comparison of wild and escaped farmed Atlantic salmon (Salmo salar L.). ICES J Mar Sci 54:1113-1119

Jaworski A, Holm JC (1992) Distribution and structure of the population of sea lice, Lepeophtheirus salmonis Kroeyer, on Atlantic salmon, Salmo salar L., under typical rearing conditions. Aquacult Fish Manage 23: 577-589

> Johnson SC, Albright LJ (1991a) Development, growth, and survival of Lepeophtheirus salmonis (Copepoda, Caligidae) under laboratory conditions. J Mar Biol Assoc UK 71:425-436

> Johnson SC, Albright LJ (1991b) The developmental stages of Lepeophtheirus salmonis (Krøyer, 1837) (Copepoda, Caligidae). Can J Zool 69:929-950

Johnson SC, Treasurer JW, Bravo S, Nagasawa K, Kabata Z (2004) A review of the impact of parasitic copepods on marine aquaculture. Zool Stud 43:229-243

> Jones MW, Sommerville C, Wootten R (1992) Reduced sensitivity of the salmon louse, Lepeophtheirus salmonis, to the organophosphate dichlorvos. J Fish Dis 15:197-202

Lees F, Baillie M, Gettinby G, Revie CW (2008) The efficacy of emamectin benzoate against infestations of Lepeophtheirus salmonis on farmed Atlantic salmon (Salmo salar L) in Scotland, 2002-2006. PLoS ONE 3(2):e1549

Morton A, Routledge R (2005) Mortality rates for pink Oncorhynchus gorbuscha and chum O. keta salmon infested with salmon louse Lepeophtheirus salmonis in the Broughton Archipelago. Alsk Fish Res Bull 11: $146-152$

> Pike AW, Wadsworth SL (1999) Sealice on salmonids: their biology and control. Adv Parasitol 44:233-337

> Rae GH (2002) Sea louse control in Scotland, past and present. Pest Manag Sci 58:515-520

Raynard RS, Bricknell IR, Billingsley PF, Nisbet AJ, Vigneau A, Sommerville C (2002) Development of vaccines against sea lice. Pest Manag Sci 58:569-575

Ritchie G (1997) The host transfer ability of Lepeophtheirus salmonis (Copepoda: Caligidae) from farmed Atlantic salmon, Salmo salar L. J Fish Dis 20:153-157

> Roper J, Grayson TH, Jenkins PG, Hone JV, Wrathmell AB, Russell PM, Harris JE (1995) The immunocytochemical localization of potential candidate vaccine antigens from the salmon louse Lepeophtheirus salmonis (Kroyer 1837). Aquaculture 132:221-232

- Sevatdal S, Horsberg TE (2003) Determination of reduced sensitivity in sea lice (Lepeophtheirus salmonis Krøyer) against the pyrethroid deltamethrin using bioassays and probit modelling. Aquaculture 218:21-31

Sevatdal S, Copley L, Wallace C, Jackson D, Horsberg TE (2005) Monitoring of the sensitivity of sea lice (Lepeophtheirus salmonis) to pyrethroids in Norway, Ireland and Scotland using bioassays and probit modelling. Aquaculture 244:19-27

Tingley GA, Ives MJ, Russell IC (1997) The occurrence of lice on sea trout (Salmo trutta L.) captured in the sea off 
the East Anglian coast of England. ICES J Mar Sci 54: 1120-1128

Todd CD, Walker AM, Hoyle JE, Northcott SJ, Walker AF, Ritchie MG (2000) Infestations of wild adult Atlantic salmon (Salmo salar L.) by the ectoparasitic copepod sea louse Lepeophtheirus salmonis Krøyer: prevalence, intensity and the spatial distribution of males and females on the host fish. Hydrobiologia 429: 181-196

Todd CD, Walker AM, Ritchie MG, Graves JA, Walker AF (2004) Population genetic differentiation of sea lice (Lepeophtheirus salmonis) parasitic on Atlantic and Pacific salmonids: analyses of microsatellite DNA variation among wild and farmed hosts. Can J Fish Aquat Sci 61: 1176-1190

Todd CD, Stevenson RJ, Reinardy H, Ritchie MG (2005) Polyandry in the ectoparasitic copepod Lepeoph-

Editorial responsibility: Sven Klimpel, Frankfurt, Germany theirus salmonis despite complex precopulatory and postcopulatory mate-guarding. Mar Ecol Prog Ser 303:225-234

Tucker CS, Norman R, Shinn AP, Bron JE, Sommerville C, Wootten R (2002a) A single cohort time delay model of the life-cycle of the salmon louse Lepeophtheirus salmonis on Atlantic salmon Salmo salar. Fish Pathol 37: 107-118

Tucker CS, Sommerville C, Wootten R (2002b) Does size really matter? Effects of fish surface area on the settlement and initial survival of Lepeophtheirus salmonis, an ectoparasite of Atlantic salmon Salmo salar. Dis Aquat Org 49:145-152

Westcott JD, Hammell KL, Burka JF (2004) Sea lice treatments, management practices and sea lice sampling methods on Atlantic salmon farms in the Bay of Fundy, New Brunswick, Canada. Aquacult Res 35:784-792

Submitted: February 23, 2011; Accepted: July 18, 2011 Proofs received from author(s): October 14, 2011 